\title{
Desenvolvimento de mudas de açaí em diferentes tipos de substrato
}

\author{
Development of açaí seedlings on different types of substrate \\ Desarrollo de plántulas de açaí en diferentes tipos de sustrato
}

Recebido: 11/08/2021 | Revisado: 19/08/2021 | Aceito: 23/09/2021 | Publicado: 24/09/2021

\author{
Anabelle Bueno Oliveira \\ ORCID: https://orcid.org/0000-0002-0153-4659 \\ Universidade Federal de Goiás, Brasil \\ E-mail: anabellebueno@ discente.ufg.br \\ Jaqueline Lima da Conceição Souza \\ ORCID: https://orcid.org/0000-0003-1829-2665 \\ Universidade Federal de Goiás, Brasil \\ E-mail: jaquelinesouzaagro@gmail.com \\ Muza do Carmo Vieira \\ ORCID: https://orcid.org/0000-0003-1730-9541 \\ Instituto Federal Goiano, Brasil \\ E-mail: mcvmuza@gmail.com \\ Rosângela Vera \\ ORCID: https://orcid.org/0000-0003-2415-3928 \\ Universidade Federal de Goiás, Brasil \\ E-mail: vera@ufg.br \\ Eli Regina Barboza de Souza \\ ORCID: https://orcid.org/0000-0001-6225-6122 \\ Universidade Federal de Goiás, Brasil \\ E-mail: eliregina@ufg.br
}

\begin{abstract}
Resumo
Euterpe oleracea Mart. é uma palmeira nativa da Amazônia, conhecida popularmente por açaizeiro. Esta espécie apresenta grande importância econômica na região, influenciando e movimentando seus grandes mercados. Seu cultivo é voltado para a produção de frutos e palmito. O açaí nos últimos anos é consumido em grande escala em diversas regiões do Brasil e vem se consolidando nos mercados nacionais e internacionais. Com o crescimento desse mercado, houve também o aumento no interesse na produção de mudas de qualidade a fím de atender essa demanda. Assim, objetivou avaliar o uso de diferentes composições de substrato no desenvolvimento de mudas de açaí. O experimento foi conduzido em telado com $50 \%$ de sombreamento localizado na UFG, com o delineamento experimental inteiramente casualizado com 3 tratamentos e 6 repetições. Os substratos utilizados foram: T1 - Padrão EMBRAPA: $20 \%$ esterco $+20 \%$ serragem $+60 \%$ solo; $\mathrm{T} 2-20 \%$ areia $+20 \%$ de esterco $+60 \%$ de substrato comercial; e T3 $-20 \%$ de areia $+20 \%$ de esterco $+20 \%$ de solo. Foram obtidos dados de: altura das mudas, diâmetro do caule, número de folhas, massa de matéria fresca e seca e índice relativo da clorofila. Realizou-se análises nos substratos para a determinação da densidade, capacidade de retenção de água, pH e condutividade elétrica. Verificouse que os substratos apresentaram resultados semelhantes, possibilitando o uso de qualquer um deles, de acordo com a facilidade de obtenção.
\end{abstract}

Palavras-chave: Euterpe oleracea; Propagação sexuada; Biometria.

\begin{abstract}
Euterpe oleracea Mart. is a palm tree native to the Amazon, popularly known as açaizeiro. This species has great economic importance in the region, influencing and moving its large markets. Its cultivation is aimed at the production of fruits and hearts of palm. Açaí in recent years has been consumed on a large scale in several regions of Brazil and has been consolidating in national and international markets. With the growth of this market, there was also an increase in interest in the production of quality seedlings in order to meet this demand. Thus, it aimed to evaluate the use of different substrate compositions in the development of açaí seedlings. The experiment was conducted in a greenhouse with 50\% shading located in the UFG, with a completely randomized design with 3 treatments and 6 replications. The substrates used were: T1 - EMBRAPA Standard: $20 \%$ manure $+20 \%$ sawdust $+60 \%$ soil; T2 $20 \%$ sand $+20 \%$ manure $+60 \%$ commercial substrate; and $\mathrm{T} 3-20 \%$ sand $+20 \%$ manure $+20 \%$ soil. Data were obtained from: seedling height, stem diameter, number of leaves, fresh and dry matter mass and relative chlorophyll index. Analyzes were performed on the substrates to determine density, water holding capacity, $\mathrm{pH}$ and electrical conductivity. It was found that the substrates showed similar results, allowing the use of any of them, according to the ease of obtaining.
\end{abstract}

Keywords: Euterpe oleracea; Sexual propagation; Biometrics. 


\section{Resumen}

Euterpe oleracea Mart. es una palmera originaria del Amazonas, popularmente conocida como açaizeiro. Esta especie tiene una gran importancia económica en la región, influyendo y moviendo sus grandes mercados. Su cultivo está orientado a la producción de frutos y palmito. El Açaí en los últimos años se ha consumido a gran escala en varias regiones de Brasil y se ha ido consolidando en los mercados nacionales e internacionales. Con el crecimiento de este mercado, también se incrementó el interés en la producción de plántulas de calidad para atender esta demanda. Así, tuvo como objetivo evaluar el uso de diferentes composiciones de sustrato en el desarrollo de plántulas de açaí. El experimento se realizó en un invernadero con 50\% de sombra ubicado en la UFG, con un diseño completamente al azar con 3 tratamientos y 6 repeticiones. Los sustratos utilizados fueron: T1 - Estándar EMBRAPA: 20\% estiércol + $20 \%$ aserrín $+60 \%$ tierra; T2 $-20 \%$ arena $+20 \%$ estiércol $+60 \%$ sustrato comercial; y T3 $-20 \%$ arena $+20 \%$ estiércol $+20 \%$ suelo. Los datos se obtuvieron de: altura de la plántula, diámetro del tallo, número de hojas, masa de materia fresca y seca e índice relativo de clorofila. Se realizaron análisis sobre los sustratos para determinar la densidad, la capacidad de retención de agua, el $\mathrm{pH}$ y la conductividad eléctrica. Se encontró que los sustratos mostraron resultados similares, permitiendo el uso de cualquiera de ellos, según la facilidad de obtención.

Palabras clave: Euterpe oleracea; Propagación sexual; Biometría.

\section{Introdução}

O Brasil é o maior produtor do mundo de açaí (Euterpe oleracea Mart.). Esta espécie possui ampla distribuição geográfica na América Latina e encontra-se em grande abundância no bioma Amazônico. O açaí pode ser utilizado em forma de suco e deste modo faz parte da base alimentar de muitas famílias nos estados da região Norte. Nos últimos anos tem sido difundido no restante do país (Silva et al., 2020).

O açaí está dentre as espécies mais promissoras para o mercado nacional e internacional. Apresenta importância econômica com uma gama de produtos, como, polpa da fruta, artesanato, adubos e corantes; e social, pois exibe um valor cultural às comunidades tradicionais entre elas a ribeirinha. Sua relevância ambiental está relacionada ao fato de compor a paisagem e a diversidade florística, servir de alimento para a fauna e a ciclagem de nutrientes (D’Arace et al., 2019).

Segundo Silva et al. (2017) o aumento da demanda dos frutos de açaí deve-se às propriedades nutricionais e ao valor calórico, já que este pode ser considerado como um alimento rico em proteínas, lipídeos, vitamina E, e minerais (manganês, cobre, boro e cromo). Assim, o interesse econômico e social está atribuído especialmente, às suas propriedades antioxidantes e composição fotoquímica.

Diante das diversas aplicabilidades da espécie, a procura por mudas têm sido crescente. A produção de mudas ocorre primordialmente por sementes, e a propagação vegetativa é de difícil operacionalização (Cesarin et al., 2020). A estrutura utilizada como semente é o endocarpo que possui em seu interior uma semente que reduz a viabilidade rapidamente, uma vez que é recalcitrante. Sua germinação é rápida e desuniforme. A emergência das plântulas normalmente inicia aos 20-30 dias após a semeadura e finaliza aos 50-60 dias. Quando processadas de forma adequada as sementes exibem índice de germinação superior a $80 \%$ (Vieira et al., 2018).

No intuito de atender a demanda da produção de frutos, para processamento, é necessária a utilização de mudas de qualidade e que atenda a expectativa do produtor na condução de cultivo dessa espécie. Um dos fatores a ser avaliado na produção de mudas de espécies de plantas é o substrato. Na escolha do substrato é relevante que alguns fatores sejam levados em consideração, tais quais os de ordem econômica e técnica (química e física) do material. Dentre os fatores de ordem econômica são incluídos os termos de custo, disponibilidade, qualidade e facilidade de manuseio. Já os de ordem química atribuem-se ao pH e ao nível de fertilidade do material. Os fatores físicos são a granulometria e densidade, dentre outros, que interferem na aeração, capacidade de retenção de umidade e agregação do substrato (Wendling \& Dutra, 2018).

Nesse contexto, objetivou-se avaliar o efeito de diferentes tipos de substratos no desenvolvimento de mudas de açaí no estado de Goiás. 


\section{Metodologia}

O experimento foi instalado e conduzido em telado, com 50\% de sombreamento, na Escola de Agronomia na Universidade Federal de Goiás, em Goiânia-GO (Latitude $16^{\circ} 35^{\prime} 47,32^{\circ}$, Longitude $49^{\circ} 16^{\prime} 47,83^{\circ}$ ). O clima da região é tropical, com temperatura média de $23,1^{\circ} \mathrm{C}$.

O delineamento experimental foi inteiramente casualizado, sendo três tratamentos (substratos), com 6 repetições e cada repetição composta por 5 embalagens. Foram utilizadas embalagens plásticas perfuradas e sanfonadas próprias para a produção de mudas. As sementes foram embebidas em água por um período de sete dias, como tratamento de escarificação, descrito em outro estudo sobre germinação de sementes de açaí. Posteriormente foram semeadas em bandejas plásticas contendo como substrato vermiculita.

O processo de germinação teve início aos 18 dias e término aos 49 dias após a semeadura. Logo após as mudas foram transplantadas para os sacos plásticos preto de polietileno (Figura 1).

Figura 1. Sementes após pré-germinação na vermiculita (A). Instalação de experimento com os sacos preenchidos com substrato (B).
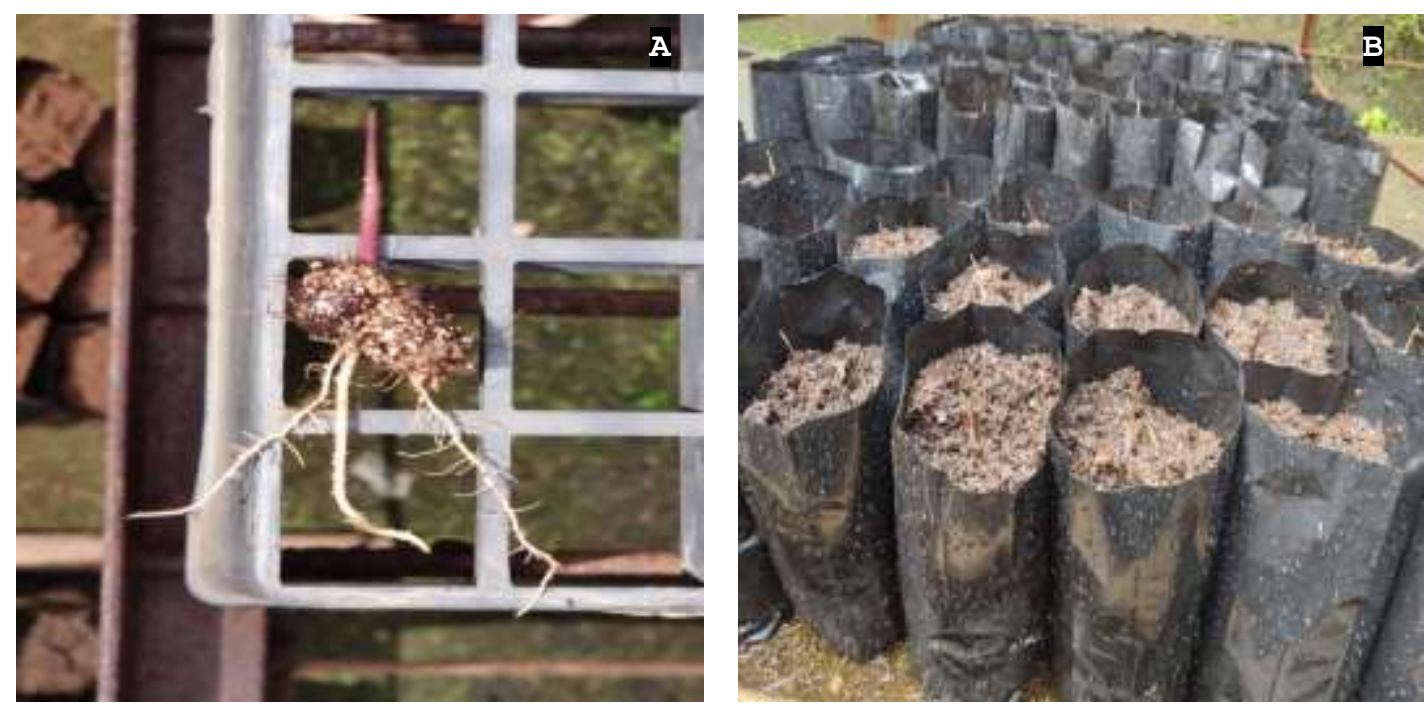

Fonte: Autores.

Os tratamentos foram três tipos de substratos: T1 - Padrão EMBRAPA: $20 \%$ de esterco $+20 \%$ de serragem $+60 \%$ de solo; $\mathrm{T} 2-20 \%$ areia $+20 \%$ de esterco $+60 \%$ de substrato comercial e T3 $-20 \%$ de areia $+20 \%$ de esterco $+60 \%$ de solo.

As análises nos substratos foram realizadas para a determinação da densidade, determinação da capacidade de retenção de água, pH, relação poros/sólidos e condutividade elétrica dos substratos de acordo com Takane et al. (2013).

A análise biométrica das mudas foi realizada aos, 30;60;90;120;150; 180 e 330 dias após o transplante das mudas sendo avaliadas:

- Altura das mudas $(\mathrm{cm})$ : com auxílio de régua graduada medindo-se o comprimento do caule a partir da 0,5 cm superfície do substrato até a inserção da folha mais nova.

- Diâmetro do caule (mm): com a utilização de um paquímetro digital, colocado a aproximadamente $0,5 \mathrm{~cm}$ da superfície do substrato.

A massa de matéria fresca e seca da parte aérea e da raiz (g) foi realizada ao final do experimento (330 dias). As plantas foram retiradas da embalagem e lavadas (Figura 2). Em seguida foi separada a parte aérea (folhas e caule) do sistema 
radicular para pesagem. Posteriormente foram colocadas em sacos de papel e levadas até uma estufa de circulação forçada de ar a $60^{\circ} \mathrm{C}$, até a obtenção de peso constante. Logo após, foi realizada nova pesagem em balança de precisão.

Figura 2. Avaliação de massa fresca da raiz e parte aérea das mudas de açaí em cada tratamento. (A): Tratamento $1=20 \%$ esterco $+20 \%$ serragem $+60 \%$ solo; $(\mathrm{B})$ : Tratamento $2=20 \%$ areia $+20 \%$ esterco $+60 \%$ substrato comercial; e $(\mathrm{C})$ : Tratamento $3=20 \%$ areia $+20 \%$ esterco $+60 \%$ solo .

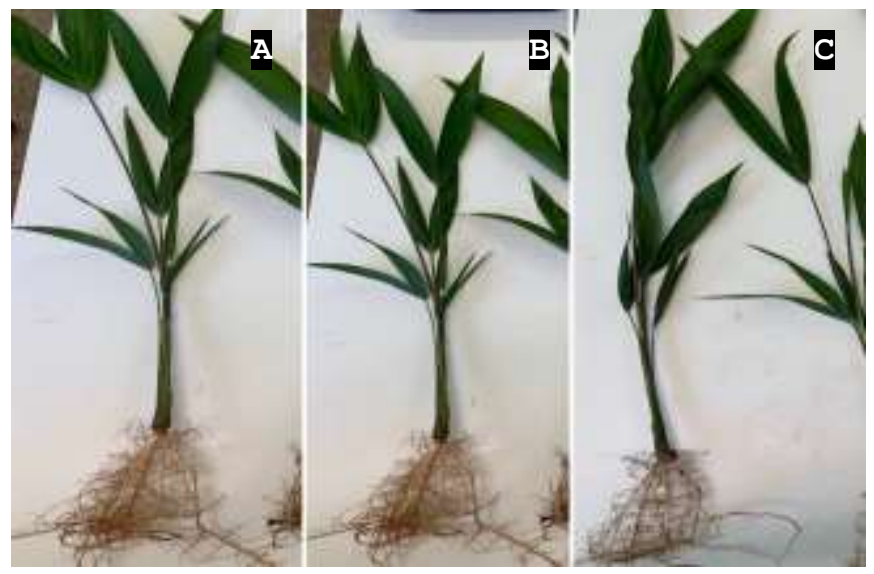

Fonte: Autores.

O Índice relativo de clorofila foi obtido com auxílio do aparelho Clorofilog CFL1030. Foram realizadas duas avaliações, sendo a primeira aos 180 dias e a segunda aos 330 dias após o transplante das mudas.

Os resultados obtidos foram analisados por meio de análise de variância, constatando diferenças significativas, foi realizado o Teste Tukey a 1\% e 5\% de probabilidade. Foi utilizado o software Sisvar (Ferreira, 2011).

\section{Resultados e Discussão}

Não foram constatadas diferenças significativas a $1 \%$ e $5 \%$ entre os substratos para as variáveis altura, diâmetro e número de folhas. Observa-se que o maior incremento mensal de desenvolvimento da muda em altura, foi obtido nos meses finais em todos os tratamentos (Figura 3). Este resultado pode estar relacionado ao fato das plantas nesta fase terem atingido tamanho de folhas superior em relação aos períodos anteriores. Normalmente, quando as plantas atingem tamanho de folha máximo apresentam também taxas fotossintéticas maiores (Lima Filho et al., 2009).

De acordo com Kliewer (1981) apud Lima Filho et al. (2009) o aumento da atividade fotossintética e, consequentemente do acúmulo de açucares nas folhas em expansão, ocorre em razão do aumento do teor de clorofila por unidade de área foliar, ao aumento da atividade de enzimas carboxilativas e à diminuição da resistência estomática.

A altura do Tratamento 3 (20\% areia, 20\% esterco e 60\% solo) e do Tratamento 2 composto por 20\% areia, 20\% esterco e $60 \%$ de substrato comercial, apresentaram valores de incrementos crescentes entre os meses, exceto no último. O Tratamento 1 padrão Embrapa, composto por 20\% de esterco, 20\% serragem e $60 \%$ solo, diferiu dos demais e apresentou incremento de altura variável mês a mês (Figura 3).

Um dos motivos que pode explicar o resultado do substrato do Tratamento 1 é a serragem de madeira, por possuir uma relação $\mathrm{C} / \mathrm{N}$ elevada é de difícil decomposição. Ela também pode conter muita resina e pouco teor de fósforo (P) e potássio $(\mathrm{K})$.

Os tratamentos 2 e 3 em que ambos apresentam em sua composição o material areia, demonstraram maior incremento de diâmetro nos últimos períodos de avaliação. De acordo com Gomes \& Paiva (2006) a areia facilita o processo de drenagem. 
Os autores relatam ainda que a terra auxilia na boa agregação e retenção de água e a presença de material orgânico contribui tanto no processo de agregação quanto no aumento da capacidade de retenção de água. Também aumenta a capacidade de troca catiônica.

Em relação ao número de folhas, todos os substratos responderam de forma semelhante. Nos três primeiros meses, apresentaram em média 2 folhas e a partir do quarto mês, 4 folhas.

Figura 3. Incremento mensal da altura e diâmetro de mudas de açaizeiro submetidas a diferentes substratos, durante os meses de junho a novembro de 2020 .
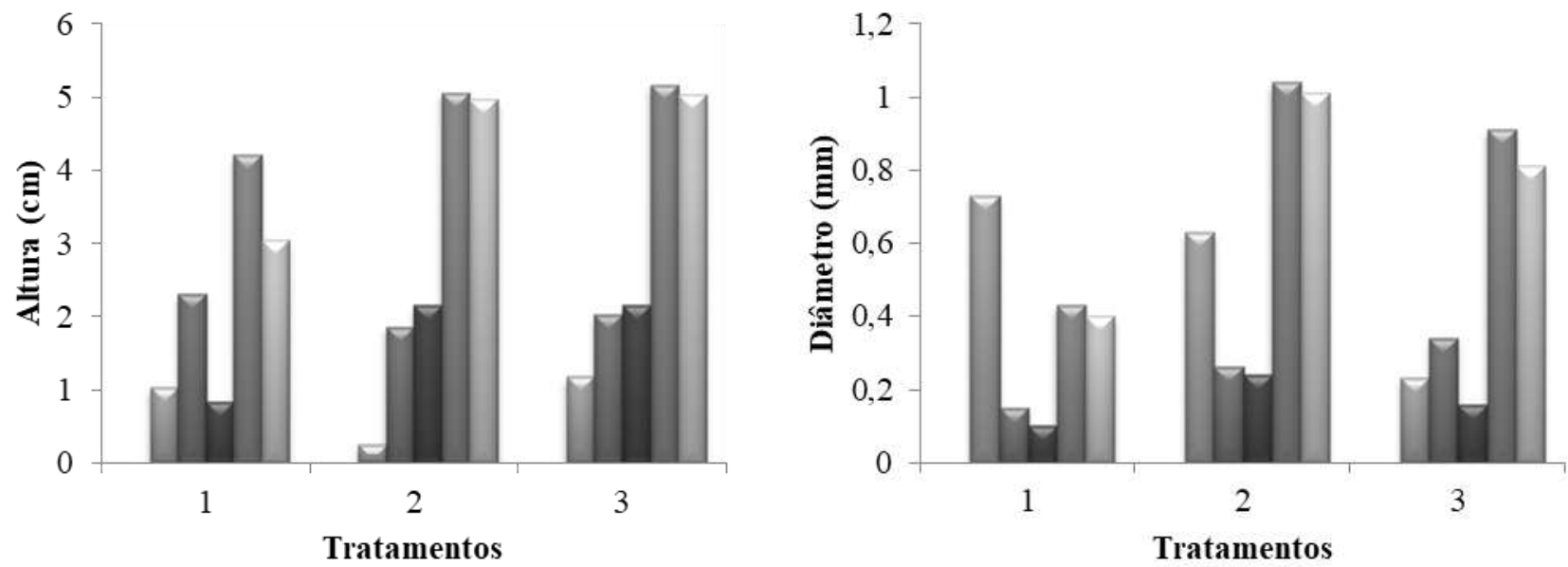

*Cada coluna diz respeito ao incremento obtido em cada mês (julho; agosto; setembro; outubro e novembro). Fonte: Autores.

O índice relativo de clorofila não apresentou efeito significativo entre os tratamentos (Tabela 1). O valor médio desta variável foi $39,60 \mu \mathrm{g} \mathrm{cm}^{2}$.

Tabela 1. Valores médios do teor da clorofila de mudas de açaizeiro avaliadas ao final de seis meses, em diferentes substratos.

\begin{tabular}{cc}
\hline Tratamento & Teor de clorofila $\left(\mu \mathrm{g} \mathrm{cm}{ }^{2}\right)$ \\
\hline 1 & $31,47 \mathrm{a}$ \\
2 & $40,22 \mathrm{a}$ \\
3 & $41,88 \mathrm{a}$ \\
\hline
\end{tabular}

Tratamento $1=20 \%$ esterco $+20 \%$ serragem $+60 \%$ solo; Tratamento $2=20 \%$ areia $+20 \%$ esterco $+60 \%$ substrato comercial; Tratamento 3 $=20 \%$ areia $+20 \%$ esterco $+60 \%$ solo. Fonte: Autores.

Observou-se que aos 330 dias após o transplante das mudas para os sacos plásticos de polietileno houve diferença significativa a $5 \%$ de probabilidade. O substrato 3 demonstrou-se superior ao 1 para altura e também para teor de clorofila (Tabela 2).

Sousa et al. (2018) ao avaliarem o efeito de diferentes tipos de substrato para a produção de mudas de açaí observaram que os tratamentos compostos por esterco bovino nas proporções de $50 \%$ de esterco bovino $+50 \%$ de areia; $25 \%$ de areia mais $75 \%$ de esterco bovino e $25 \%$ de substrato comercial Bioplant $+75 \%$ de esterco bovino demonstraram ser melhores quando considerou o crescimento em altura e diâmetro do coleto. Ainda, aumentaram a produção de massa seca total das mudas de açaí. 
Segundo Queiroz et al. (2001) a muda no momento em que é retirada do viveiro, necessita estar além de vigorosa e sadia, com altura de 40 a $50 \mathrm{~cm}$ e diâmetro de colo superior a $12 \mathrm{~mm}$. Comparando com os resultados obtidos, os tratamentos 2 e 3 estão de acordo com a recomendação e o Tratamento 1 com valor menor, porém muito próximo.

Para teor de clorofila, os Tratamentos 2 e 3 apresentaram melhores resultados com 47,26 e 46,67 $\mu \mathrm{g} \mathrm{cm}{ }^{2}$, respectivamente, e o tratamento $3 \mathrm{com} 40,74 \mu \mathrm{g} \mathrm{\textrm {cm } ^ { 2 }}$. O número de folhas e o diâmetro de caule não teve diferença significativa entre si.

De acordo com a Comissão Estadual de Sementes e Mudas do Pará (1997), as mudas de açaizeiro devem apresentar no mínimo cinco folhas fisiologicamente maduras, então nesse parâmetro todos os tratamentos se enquadraram nessa característica.

Tabela 2. Valores médios de altura, número de folhas, diâmetro do caule e teor de clorofila de mudas de açaizeiro avaliadas um ano após a instalação do experimento.

\begin{tabular}{ccccc}
\hline Tratamento & $\begin{array}{c}\text { Altura } \\
(\mathrm{cm})\end{array}$ & Número de Folhas & $\begin{array}{c}\text { Diâmetro do caule } \\
(\mathrm{mm})\end{array}$ & $\begin{array}{c}\text { Teor de clorofila } \\
\left.(\mu \mathrm{g} \mathrm{cm})^{2}\right)\end{array}$ \\
\hline 1 & $39,63 \mathrm{~b}$ & $9,00 \mathrm{a}$ & $11,84 \mathrm{a}$ & $40,74 \mathrm{~b}$ \\
2 & $41,87 \mathrm{a} \mathrm{b}$ & $10,00 \mathrm{a}$ & $13,51 \mathrm{a}$ & $46,67 \mathrm{a}$ \\
3 & $46,00 \mathrm{a}$ & $10,00 \mathrm{a}$ & $14,09 \mathrm{a}$ & $47,26 \mathrm{a}$ \\
$\mathrm{CV}(\%)$ & 8,25 & 7,86 & 15,45 & 7,37 \\
\hline
\end{tabular}

$*$ Significativo pelo teste Tukey a $5 \%$ de probabilidade; Tratamento $1=20 \%$ esterco $+20 \%$ serragem $+60 \%$ solo; Tratamento $2=20 \%$ areia + $20 \%$ esterco $+60 \%$ substrato comercial; Tratamento $3=20 \%$ areia $+20 \%$ esterco $+60 \%$ solo. Fonte: Autores.

$\mathrm{O}$ menor $\mathrm{pH}$, capacidade de retenção de água e densidade foi observado no substrato 2. Avaliar o pH em um substrato é relevante pois este influencia na disponibilidade de nutriente as plantas. Desta forma, valores inadequados, podem afetar no desenvolvimento, sobretudo sob acidez em excesso. Os ambientes ácidos apresentam quantidades menores de nutrientes disponíveis, além das plantas ficarem sujeitas à maior absorção de elementos tóxicos como alumínio e manganês (Fermino, 1999; Ludwing et al., 2014).

A Instrução Normativa n. ${ }^{\circ} 12$ de 10 de setembro de 1999 (Brasil, 1999) relata que os valores de pH que satisfazem a cultura do açaí está entre 4 a 6,20. Com base nos resultados obtidos observa-se que o substrato que melhor responde neste caso são os substratos 1 e 3, com valores de pH 6,2 e 5,81 respectivamente.

É importante também avaliar a densidade do substrato em que vai ser trabalhado, porque ele influencia no desenvolvimento das mudas desde a germinação até o estabelecimento da planta. Tem-se que levar em consideração a facilidade que o substrato vai oferecer para a emissão das raízes, a emergência e o crescimento.

O substrato que retém mais água é o Tratamento 1 composto por esterco, serragem e solo (20:20:60), seguido pelo Tratamento 3 composto por areia, esterco e solo (20:20:60), e o de menor retenção de água foi o Tratamento 2, composto por areia, esterco e substrato comercial (20:20:60). O tratamento 2 possui elementos na sua formulação que explicam a sua baixa capacidade de retenção, por exemplo, a areia. Já o Tratamento 1 possui substrato com toda sua formulação a base de elementos que respondem bem a retenção de água.

A capacidade de retenção de água (CRA) é relevante, pois os substratos devem reter água da irrigação com eficiência, uma vez que se reterem pouca água entre uma irrigação e outra, que pode ter um intervalo de várias horas, as plantas poderão passar por uma restrição hídrica, e em alguns casos sofrer estresse. Isso pode comprometer o vigor das mudas (Jorge et al., 2020).

De acordo com Takane et al. (2013), em matérias primas que são indicadas para se fazer o uso na composição de substratos, a relação P/S deve apresentar valores acima de 3. O Tratamento 1 apresenta relação P/S (Tabela 3) igual a 1, com 
$50 \%$ sólidos e 50\% poros, o Tratamento 2 apresenta uma relação P/S de 1,17, com 46\% de sólidos e 54\% de poros e o Tratamento 3 apresenta uma relação P/S de 0,79 com $56 \%$ de sólidos e $44 \%$ de poros. Com base nos valores obtidos pode-se concluir que nenhum tratamento obteve o valor considerado ideal $(\mathrm{P} / \mathrm{S}>3)$.

Tabela 3. Valores do pH, Condutividade elétrica (CE), Capacidade de retenção de água (CRA), Densidade e relação P/S dos substratos.

\begin{tabular}{cccccc}
\hline Tratamento & $\mathrm{pH}$ & $\begin{array}{c}\mathrm{CE} \\
(\mathrm{mS} / \mathrm{cm})\end{array}$ & $\begin{array}{c}\text { CRA } \\
(\%)\end{array}$ & $\begin{array}{c}\text { Densidade } \\
\left(\mathrm{kg} / \mathrm{m}^{3}\right)\end{array}$ & 1 \\
\hline 1 & 6,2 & 0,81 & 48 & 134 & P/S \\
2 & 3,3 & 1,08 & 31 & $47 \mathrm{~kg} / \mathrm{m}^{3}$ & 1,17 \\
3 & 5,81 & 0,91 & 40 & $146 \mathrm{~kg} / \mathrm{m}^{3}$ & 0,79 \\
\hline
\end{tabular}

Tratamento $1=20 \%$ esterco $+20 \%$ serragem $+60 \%$ solo; Tratamento $2=20 \%$ areia $+20 \%$ esterco $+60 \%$ substrato comercial; Tratamento 3 $=20 \%$ areia $+20 \%$ esterco $+60 \%$ solo. Fonte: Autores.

Segundo Nakagawa (1999), determinar a massa seca de plântulas é uma forma de analisar seu crescimento e avaliar com maior precisão. O que indica que uma plântula com maior massa de matéria seca seja considerada vigorosa, é o fato da transferência de matéria seca dos tecidos de reserva para o eixo embrionário.

\section{Conclusão}

Neste trabalho observam-se resultados semelhantes entre os substratos no desenvolvimento das mudas de açaí. Portanto, recomenda-se o uso de qualquer um dos três substratos de acordo com a facilidade de obtenção.

A fim de verificar diferenças significativas, é necessário avaliar composições de substratos distintas as utilizadas neste estudo. Dentre as matérias primas que podem ser utilizadas para formulação de substratos, pode-se testar a fibra de coco, húmus de minhoca, vermiculita e casca de arroz carbonizada.

\section{Agradecimentos}

À Escola de Agronomia da Universidade Federal de Goiás, pela infraestrutura para realização do ensaio.

\section{Referências}

Brasil. Ministério da Agricultura e do Abastecimento. (1999). Instrução Normativa $n^{\circ} 12$ de 10 de setembro de 1999. Regulamento Técnico geral para fixação dos padrões de identidade e qualidade para a polpa de fruta. Diário Oficial da República Federativa do Brasil.

Cesarin, V. et al. (2020). Produção de mudas de açaizeiro. Revista Agronomia Brasileira, 4, 1-7.

Comissão Estadual de Sementes e Mudas do Pará. Belém, Pará. (1997). Normas técnicas e padrões para a produção de mudas fiscalizadas no Estado do Pará. Comissão Estadual de Sementes e Mudas do Pará.

D’arace, L. M. B., Pinheiro, K. A. O., Gomes, J. M., Carneiro, F. S., Costa, N. S. L., Rocha, E. S. \& Santos, M. L. (2019). Produção de açaí na região norte do Brasil. Revista Ibero Americana de Ciências Ambientais, 10(5), 115-21.

Fermino, M. H. (1999). Aproveitamento de resíduos industriais e agrícolas como alternativas de substratos hortícolas. UFRGS. (Tese Mestrado).

Ferreira, D. F. (2011). Sisvar: a computer statistical analysis system. Ciência e Agrotecnologia, 35(6), 1039-1042.

Gomes, J. M. \& Paiva, H. N. (2006). Viveiros florestais: propagação sexuada. UFV.

Jorge, M. H. A., Melo, R. A. C., Resende, F. V., Costa, E., Silva, J. \& Guedes, I. M. R. (2020). Informações técnicas sobre substratos utilizados na produção de mudas e hortaliças. Embrapa Hortaliças.

Kliewer, W. M. (1981). Grapvine physiology: how does a grapevine maker sugar?. University of California. 
Lima Filho, J. M. P., Dantas, B., Assis, J. S., Souza, C. R. \& Albuquerque, T. C. S. (2009). Aspectos Fisiológicos. In: Soares, J. M. \& Leao, P. C. S. (Eds.). A vitivinicultura no Semiárido brasileiro. Embrapa Informação Tecnológica; Embrapa Semi-Árido.

Ludwig, F., Fernandes, D. M., Guerrero, A. C. \& Villas Bôas, R. L. (2014). Características dos substratos na absorção de nutrientes e na produção de gérbera de vaso. Horticultura Brasileira, 32, 184-189.

Nakagawa, J. (1999). Testes de vigor baseados no desenvolvimento das plântulas. In: Krzyzanoswski, F. C. H.,Vieira, R. D. \& França Neto, J. B. (Eds.). Vigor de sementes: conceitos e testes. ABRATES.

Oliveira, A. G., Costa, M. C. D. \& Rocha, S. M. B. M. (2015). Benefícios funcionais do açaí na prevenção das doenças cardiovasculares. Journal of Amazon Health Science, 1(1), 1-10.

Queiroz, J. A. L., Mochiutti, S. \& Bianchetti, A. (2001). Produção de mudas de açaí. Embrapa.

Silva, A. C. D., Smiderle, O. J., Oliveira, J. M. F. \& Silva, T. J. (2017). Tamanho da semente e substratos na produção de mudas de açaí. Adv. For. Sci., 4(4), $151-156$.

Silva, A. O. et al. (2020). Estudo da produção de açaí (Euterpe oleracea Mart): aspectos econômicos e produtivos baseados nos anos de 2015 a 2017. Braz. J. of Develop., 6(1), 1629-1641.

Sousa, R. M., Marinho, P. H. A., Honório, A. B. M., Viola, M. R., Alves, M. V. G. \& Souza, P. B. (2018). Diferentes tipos de substratos para a produção de mudas de açaí Euterpe oleracea MART. Rev. Inst. Flor., 30(1), 39-45.

Takane, R. J., Yanagisawa, S. S. \& Góis, E. A. (2013). Técnicas em substratos para a floricultura. Expressão Gráfica e Editora.

Vieira, A. H. et al. (2018). Cultivo do açaizeiro (Euterpe oleracea Martius) no Noroeste do Brasil. Embrapa Rondônia.

Wendling, I. \& Dutra, L. F. (2017). Produção de mudas de eucalipto. Embrapa 